\title{
Civilizando la selva: capital, espacio y negocio forestal en la antigua Guinea continental española, c. 1926-1936
}

\author{
Henar Pascual Ruiz-Valdepeñas y Juan Carlos Guerra Velasco
}

\begin{abstract}
PALABRAS CLAVE: Guinea Ecuatorial, compañías forestales, producción maderera, colonia.
\end{abstract}

CÓDIGOS JEL: F54, Q23, N57, F1.

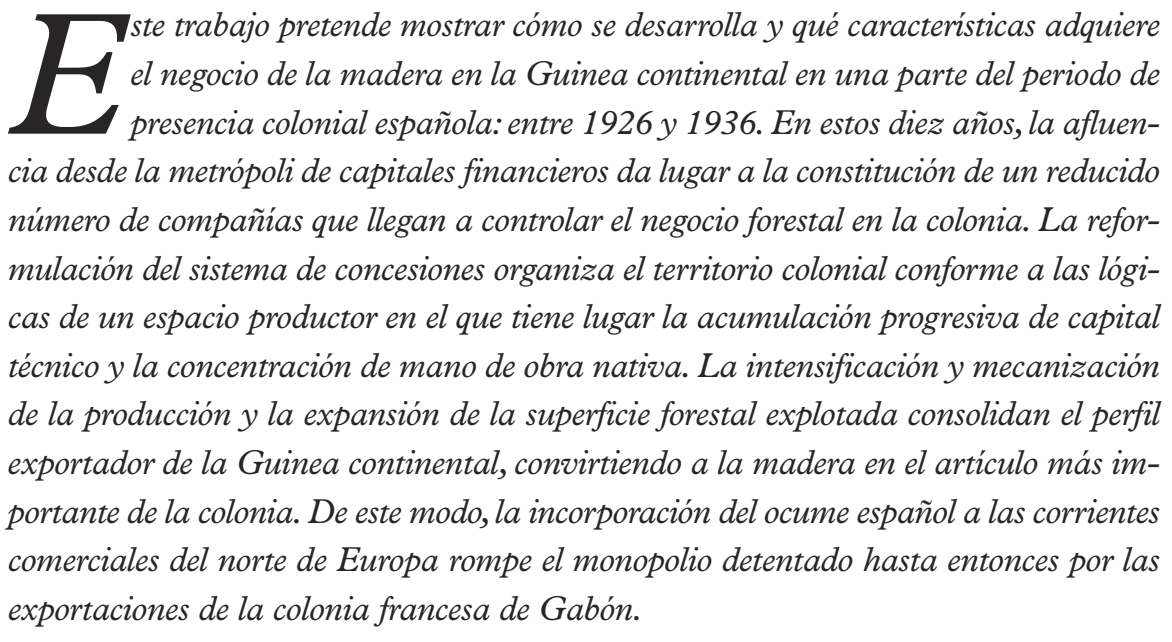




\title{
Civilizing the forest: capital, space and business in the former Spanish Continental Guinea, 1926-1936
}

\author{
KEYWORDS: Equatorial Guinea, forest companies, wood produc- \\ tion, colony.
}

JEL CODES: F54, Q23, N57, F1.

his study examines the elements and processes that defined the development
of the wood commercialization industry in Continental Guinea between
1926 and 1936. During this period an influx of Spanish capital resulted in the establishment of a limited number of companies that controlled the logging business in this Spanish colony. The implementation of a forest concession system reorganized the colony according to a logic of production involving the progressive accumulation of technical capital and the concentration of the native workforce. The intensification and mechanization of production as well as the expansion of the exploited forest surface consolidated the export profile of Continental Guinea, making wood the most important export product of the colony. Thus, the incorporation of the Spanish okoume to Northern European commercial circuits broke the monopoly that exports from the French colony of Gabon had until then.

Recibido: 2016-02-11 - Revisado: 2016-07-05 - Aceptado: 2016-08-12

Henar Pascual Ruiz-Valdepeñas es profesora titular de Geografía Humana en la Universidad de Valladolid. Dirección para correspondencia: Departamento de Geografía, Facultad de Filosofía y Letras, Universidad de Valladolid, Plaza del Campus, 47011 Valladolid (España).C.e. pascual@fyl.uva.es

Juan Carlos Guerra Velasco es profesor titular de Análisis Geográfico Regional en la Universidad de Valladolid. Dirección para correspondencia: Departamento de Geografía, Facultad de Filosofía y Letras, Universidad deValladolid, Plaza del Campus, 47011 Valladolid (España).C.e.guerra@geo.uva.es 


\section{INTRODUCCIÓN}

$\mathrm{Al}$ igual que en otras colonias europeas en África, sobre la antigua Guinea continental española se construye a lo largo de las primeras décadas del siglo xx un discurso que ensalza sus posibilidades forestales (Río, 1915; Bravo, 1925; Arija, 1930; Nájera, 1930; Puyo, 2001; Guerra \& Pascual, 2015). La conquista militar efectiva de la región del Muni en la década de 1920, la nueva orientación en la política colonial que desarrolla la dictadura de Primo de Rivera y la institucionalización normativa a partir de 1926 de un negocio maderero, que elimina la presencia de determinadas compañías comerciales extranjeras, estimulan la aparición de nuevos capitales financieros españoles en la Guinea continental. Estos capitales reforman la inserción de este espacio en la economía forestal que se desarrolla en el occidente del África ecuatorial desde los últimos años del siglo XIX (Lasserre, 1955; Rodríguez Esteban, 1996; Lanz, 2000; Coquery-Vidrovitch, 2001; Lynn, 2002; Suárez Bosa, 2014; Campos, 2005; Garrier, 2006; Nerín, 2010, 2015; Carnero \& Díaz de la Paz, 2014; Messi, 2014; Tano, 2016).

Este trabajo pretende mostrar los elementos y procesos que permiten comprender la dimensión que adquiere el negocio de la madera en la Guinea continental a lo largo de un período de tiempo concreto: el que se extiende desde, aproximadamente, 1926 hasta $1936^{1}$. Si la primera de las fechas representa la aparición de un nuevo tipo de capital y la instauración efectiva del sistema de concesiones forestales, la segunda, con la Guerra Civil y la posterior dictadura, marca el inicio de una etapa distinta en la explotación de las selvas de la colonia. En el período abarcado por este trabajo no sólo se desarrolla el grueso del entramado empresarial que rige la explotación forestal del continente, sino que tam-

1. En estos primeros años, el negocio se circunscribe a la comercialización del ocume (Aucoumea klaineana). Este árbol se distribuye por el occidente del África ecuatorial, concretamente por el sur de Camerún, Guinea Ecuatorial, Gabón y Congo. En la primera mitad del siglo xx es introducido en Costa de Marfil. Sus propiedades técnicas (ligereza y elevada resistencia) y su alto rendimiento en el proceso de desenrollo para la obtención de chapa hacen de esta madera la materia prima esencial para la producción de tablero contrachapado, que es destinado, por su uniformidad y bajo peso, a la industria aeronáutica, el revestimiento de vagones y embarcaciones, la fabricación de carrocerías de automóviles, la construcción o la fabricación de muebles. La utilización industrial del ocume en la industria europea y el nacimiento de un mercado asociado, con centros en Hamburgo y Liverpool, arranca en 1889 en el Congo francés y a partir de 1892 aparece en las estadísticas aduaneras de Gabón, convirtiéndose en poco tiempo en la principal exportación de esta colonia, con una posición relevante en el mercado internacional de maderas coloniales (LASSERRE, 1955). A mediados de la década de 1920, el comercio de ocume es un próspero negocio, una vez que se recupera la demanda de maderas después de la Primera Guerra Mundial. Desde entonces hasta finales de los años treinta, el ocume representa prácticamente la totalidad de la producción forestal de la Guinea continental. Sólo en años posteriores se inicia una significativa explotación y comercialización de otras maderas, como akon, eteng (alabó), ekun (naranjillo), asia, elelon (satén africano), ukola (de color caoba y una de las mejores maderas de Guinea), samanguilla (caoba africana) y nsu. 
bién cristaliza una parte del ideario colonial: la selva se civiliza proporcionándole, a través de su integración capitalista e industrial, un uso más elevado que el magro aprovechamiento que de ella hace el nativo.

Las fuentes utilizadas para la elaboración de este trabajo comparten diversas propiedades: proceden de agentes directamente vinculados con la empresa colonial; surgen como consecuencia de los diversos procedimientos que el hecho concesional pone en marcha, y con su consulta es posible recomponer una parte sustancial de las lógicas que el capital colonial despliega en la Guinea continental. El grueso proviene del fondo África del Archivo General de la Administración (AGA), en concreto de la documentación generada por la Dirección General de Marruecos y Colonias -o por los órganos que hasta 1936 la sustituyen-y la repatriada, proveniente del Gobierno General de los Territorios Españoles en el Golfo de Guinea, especialmente del Servicio Agronómico y el Servicio Forestal. Los tipos documentales son variados; responden por lo general a correspondencias cruzadas en las que se solicita o se da salida a algún tipo de información y no es posible reconocer en ellas series documentales sistemáticas o consistentes por su periodicidad. Como se ha indicado, la documentación surge como consecuencia del hecho concesional; en realidad está relacionada con cuatro de sus manifestaciones: el procedimiento administrativo que da lugar a una concesión forestal y a su ampliación en superficie; las transferencias de los derechos de cada concesión a los grupos empresariales que surgen en la colonia; el seguimiento del estado de las concesiones que se realiza con motivo de alguna petición de los órganos centrales del Estado; y por último, como resultado de los trabajos fiscales propios de la administración colonial, tales como embarques, pago de aranceles, contribuciones territoriales y cumplimiento de las obligaciones de producción de las empresas concesionarias.

Un complemento necesario es el aportado por el fondo Político-Social-Documentación particular del Centro Documental de la Memoria Histórica (CDMH). En él se encuentra la documentación incautada a Ramón Viguri Ruiz de Olano, destacado militante de Izquierda Republicana y director general del Banco Exterior de España entre 1931 y 1934. La empresa ALENA (Compañía Nacional de Colonización Africana) busca entre 1932 y 1933 el apoyo financiero del Banco Exterior, que realiza un análisis de la empresa con el objeto de valorar los riesgos que asume con los créditos solicitados. Los resultados poseen un indudable interés, tanto porque se oponen al discurso grandilocuente que la compañía realiza de sí misma como por el hecho de sacar a la luz prácticas y métodos de trabajo que debían de ser comunes al resto de las compañías concesionarias.

La documentación del AGA incluye no poca información cuantitativa que sirve para conocer con precisión el capital técnico que las empresas forestales ponen al servicio del 
negocio maderero y para desagregar la dimensión comercial de cada compañía. Si bien los resúmenes estadísticos que publica el Gobierno General de Guinea en 1945 contienen datos sobre la exportación de madera entre 1930 y 1936, se ha preferido utilizar una fuente alternativa: los boletines mensuales sobre el mercado de maderas de África occidental que elabora la compañía alemana de corredores de madera K. Müller \& Sohn AG. A diferencia de la primera fuente mencionada, éstos últimos permiten comparar las exportaciones del Gabón francés con las de la Guinea continental española. A su vez, incluyen los precios de cotización del ocume en el mercado de Hamburgo. La serie presentada en el texto se completa en este apartado con los datos aportados por otros corredores de madera (Wilhelm Gerkens \& Co.), extraídos de la revista La Voz de Fernando Póo.

Las fuentes hemerográficas utilizadas incluyen esa última revista, órgano de expresión entre 1910 y 1936 de la Cámara Agrícola Oficial de Fernando Póo; La Guinea Española, publicada por los misioneros claretianos entre 1903 y 1968 (a partir de esta fecha pasa a denominarse La Guinea Ecuatorial); y, por último, la revista Montes e Industrias. Las dos primeras son imprescindibles para tener noticias y comprender no pocos aspectos de la vida en la colonia. La última, una vez interrumpida la publicación de la Revista de Montes en 1927, es el único medio forestal que, desde la óptica del industrial transformador de madera, se hace eco de la explotación de las selvas de la Guinea continental.

\section{DE LA TALA INDÍGENA AL SISTEMA DE CONCESIONES FORESTALES}

A través del sistema conocido como la tala indígena, determinadas compañías comerciales inglesas y alemanas movilizan desde finales del siglo XIX en el mercado europeo una parte de las posibilidades maderables del África occidental. Bajo esa denominación se desarrolla un procedimiento por el que los factores extranjeros indican cuáles son las especies de interés (maderas nobles y ocume) y la población nativa asentada en las inmediaciones de los principales cursos fluviales apea los árboles que estima convenientes y, divididos en trozas, los transporta por flotación hasta las factorías instaladas en el litoral. Las trozas, muchas de las cuales no consiguen llegar a la costa, son adquiridas a bajo precio por los factores y pagadas normalmente en especie ${ }^{2}$. El avance en la ocupación de la Guinea continental condiciona la valoración política que se hace de la tala indígena. Si en un primer momento la tala se acepta por los recursos que en forma de aranceles aporta a la admi-

2. El pago puede incluir telas, vestidos, escopetas de chispa y otros productos que la ocupación colonial hace útiles para el nativo (VALDÉs, 1928; AGA, caja 81/6843). 
nistración colonial, poco a poco se impone la perplejidad por la incapacidad de las estructuras del Estado para encauzar los beneficios que este negocio genera conforme a los intereses económicos y comerciales españoles ${ }^{3}$. En realidad, el escenario anterior a 1926 presenta matices que desdibujan un tanto la idea de un espacio forestalmente explotado tan sólo por compañías comerciales extranjeras. Existen comerciantes españoles de madera y se desarrollan algunas iniciativas empresariales en el litoral de la Guinea continental, pero por diversas razones unos y otras tienen un corto recorrido. El principal escollo estriba en la ausencia de una naviera nacional que dé soporte al movimiento marítimo de las maderas. Esto se traduce en no pocas ocasiones en la imposibilidad de embarcar cargamentos de ocume, incluso para aquellas compañías nacidas con apoyo de capital de la metrópoli o del impulso de significados comerciantes de Fernando Póo ${ }^{4}$.

En cualquier caso, lo relevante es que la ausencia de un modelo de negocio forestal que contrarreste el peso del binomio tala indígena/capitalismo comercial hace que se asiente con firmeza un doble discurso: el del expolio extranjero al que se ven sometidas las selvas de Guinea y el de la necesidad de sustituir el extractivismo forestal inherente a la tala indígena por otro de corte nacional. Este cambio se produce a partir de la segunda mitad de la década de 1920. Las oportunidades de negocio que se vislumbran con el lucrativo negocio del ocume hacen que se reformulen algunas de las estructuras jurídicas que desde el Real Decreto de 11 de julio de 1904 regulan la propiedad territorial y la explotación de la selva ${ }^{5}$. La Real Orden de 1 de marzo de 1926 reconoce la manifiesta imprecisión de la ocupación y explotación de terrenos y bosques a la vez que señala la posibilidad de reconocimiento de cada predio ocupado o explotación arbórea emprendida por medio de los puestos de la Guardia Colonial en sus demarcaciones respectivas ${ }^{6}$. Estos dos hechos,

3. Las maderas de Guinea, con independencia del tipo aplicado a lo largo del tiempo, pagan derechos de exportación cuando salen de la colonia y aranceles de importación al llegar a los puertos metropolitanos (AGA, cajas 81/6410, 81/6435, 81/6843).

4. Es el caso de la Compañía Hispano Africana Oliva y Traval o de Forestal de Río Benito. Ambas cuentan con la participación de Vicente Barrantes, fundador y secretario durante mucho tiempo de la Cámara Agrícola Oficial de Fernando Póo. Las dos cesan su actividad en 1926 (La Guinea Española, 25/03/1913, 25/02/1917, 10/12/1921).

5. El Real Decreto de 11 de julio de 1904 sobre el régimen de propiedad en los territorios españoles en el golfo de Guinea reafirma el carácter de propiedad privada del Estado de todas aquella propiedades que no hayan pasado nunca al dominio de particulares en virtud de concesiones gratuitas u onerosas por parte de las autoridades competentes, establece su régimen de concesión y se exceptúan de este procedimiento las tierras que hayan sido demarcadas como propiedad de tribus, poblados o grupos familiares indígenas, en la forma y condiciones que determina este decreto. Del mismo modo, la norma permite el acceso al sistema concesional de reparto de la tierra al capital extranjero (Real Decreto de 11 de julio de 1904, arts. 4, 18; Gaceta de Madrid, 12/04/1904).

6. La Guardia Colonial concluye su despliegue por la Guinea continental unos años antes, después de "pacificar", en ocasiones con una gran violencia, el norte de la colonia (NeRíN, 2010). 
junto con la necesidad de reforzar los contenidos que persiguen una «ordenada» obtención de los productos forestales del Real Decreto de 11 de julio de 1904 y de vincular de una manera efectiva la explotación y dominio del espacio con la condición de concesionario, llevan a la desaparición de la tala indígena a través de la prohibición de la corta y exportación de madera a todo el que carezca de autorización del Gobierno para ello y la circulación y embarque de aquellas que no lleven la guía necesaria a los efectos del artículo anterior. El título de concesionario es el que faculta de una manera inequívoca para explotar la colonia; y a éste, una vez que se declaran caducados por Real Decreto de 5 de mayo de 1926 los derechos precedentes si no se ha cumplido lo dispuesto en cada orden de concesión, sólo se puede acceder si el peticionario está radicado en España y un $75 \%$ del capital pertenece de modo intransferible o nominativo a ciudadanos españoles en el caso de sociedades ${ }^{7}$.

\section{LA ENTRADA DE LOS CAPITALES FINANCIEROSY LA CONSTITUCIÓN DE LAS COMPAÑÍAS FORESTALES}

Los cambios en el régimen de propiedad territorial y en el de explotación de la selva impulsan el proceso de extracción de madera y abren un período jalonado por la demarcación de un total de 110.000 hectáreas en grandes lotes forestales a lo largo del litoral y en los tramos bajos de los principales ríos de la Guinea continental (Guerra \& Pascual, 2015) (Figura 1). El entramado societario al que da soporte la posesión de estos lotes se levanta en un corto período de tiempo a través de tres vías: reconociendo los derechos no caducados de las compañías que operan en el continente desde unos años antes; obteniendo concesiones a título particular que más tarde se aportan como activos a las nuevas empresas que se constituyen; y adquiriendo sociedades ya formadas.

7. El procedimiento que regula la adjudicación de una concesión se inicia con la solicitud por parte del peticionario y ante la Dirección General de Marruecos y Colonias de una superficie de terreno sobre la que debe concretarse su emplazamiento, linderos, extensión y la descripción de las circunstancias que puedan hacerla reconocible. Una vez recabados los preceptivos informes del Servicio Agronómico (después del Servicio Forestal) y del gobernador general de la colonia, se procede a la publicación del pliego de condiciones para la subasta. Ésta contempla su otorgamiento a título temporal (20 años) y oneroso mediante derecho de tanteo en favor del primer peticionario. Entre las obligaciones del concesionario se incluye la designación de un perito a disposición de la administración colonial para proceder a la delimitación definitiva del terreno y la presentación del plano de deslinde en un plazo de doce meses; el concesionario debe someter también a la aprobación del Servicio Forestal de la colonia las normas de la explotación, así como respetar el arbolado y las plantaciones precisas a las necesidades de los indígenas enclavados en la concesión, reservando a este fin al menos dos hectáreas por cabeza de familia (Real Decreto de 5 de mayo de 1926, art. 6). 


\section{FIGURA 1}

Localización de las concesiones forestales en la antigua Guinea continental española (1926-1936)

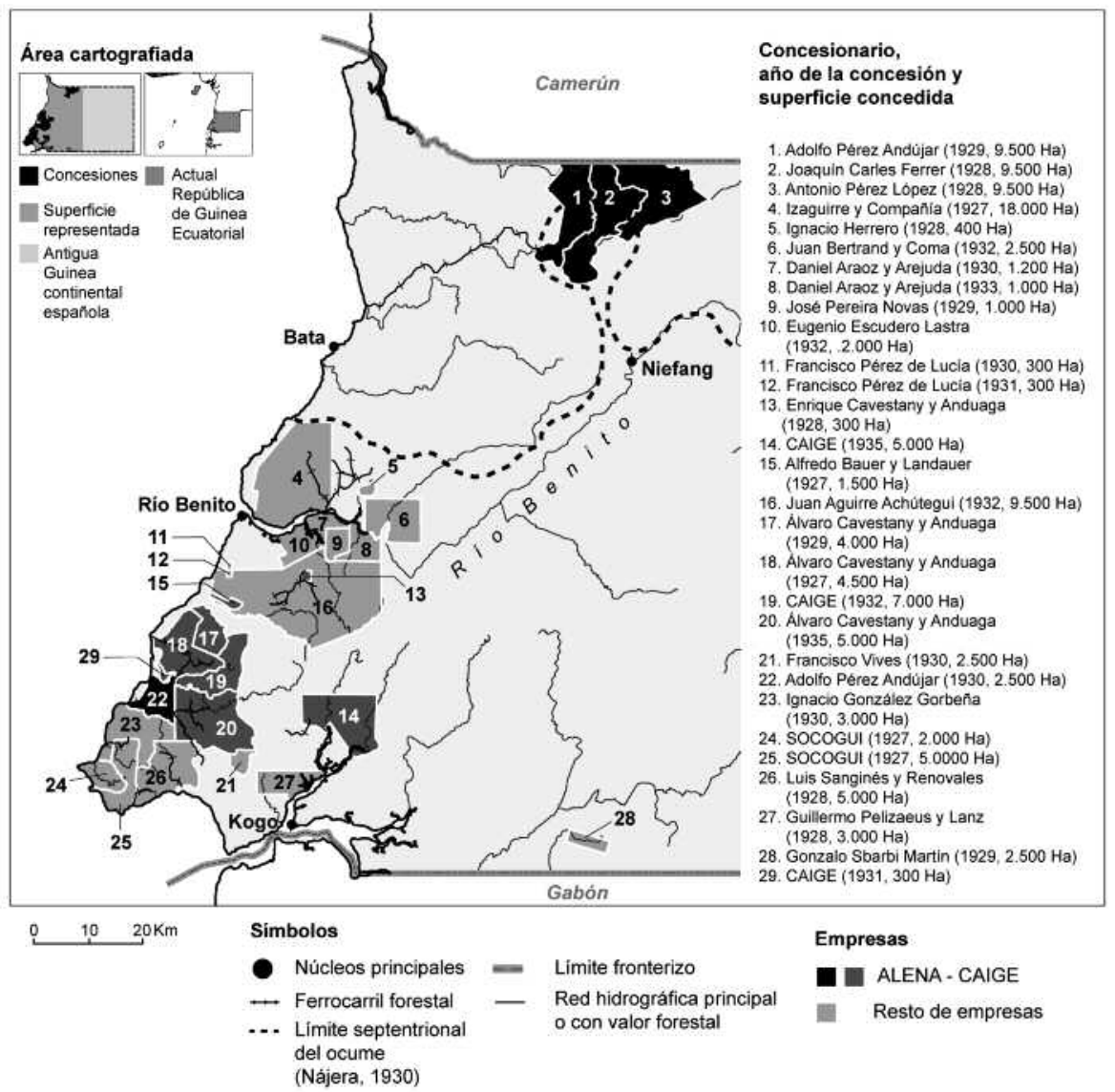

Fuente: elaboración propia a partir de la digitalización parcial de la Carta Itineraria de la Guinea Continental Española a escala 1:200.000 (1951) y de diversos legajos del AGA para el dibujo de las concesiones (19261936)

La primera vía la representan empresas como Izaguirre y Compañía y SOCOGUI (Sociedad Colonial de Guinea). En el primero de los casos se convalida una concesión de 10.000 hectáreas situada en la margen derecha de la desembocadura del río Benito (2.000 en propiedad y 8.000 como subvención por las obras de interés general acometidas en los años precedentes), más la posibilidad de ampliarla sobre los terrenos limítrofes en una superficie semejante ${ }^{8}$. SOCOGUI ve cómo se reconocen las 2.000 hectáreas que

8. El espacio de la Guinea continental es para el peticionario de concesiones un espacio plano, en el que la única limitación son las posibilidades de explotación que abre el capital que aporta. No exis- 
ocupa en la cuenca del río Naño en Cabo San Juan (al sur de la colonia) y se le reserva el derecho a obtener otra concesión forestal de 5.000 hectáreas como ampliación de la anterior ${ }^{9}$.

El segundo camino de entrada al negocio forestal, por el que los adjudicatarios originales se convierten en accionistas mediante la aportación de sus respectivas concesiones, es el que utilizan empresas como CAIGE (Compañía Agrícola e Industrial de la Guinea Española), AGGOR, PROHISCO (Productora Hispano-Colonial) y Compañía de Maderas de Río Benito ${ }^{10}$. La primera se arma en torno a las 9.500 hectáreas que entre 1927 y 1929 consigue Rafael Cavestany más la aportación de 1,7 millones de pesetas provenientes de la casa Bauer y Cía., representante en España de la Casa Rothschild (López Morell, 2005) ${ }^{11}$. En la firma de capital vasco AGGOR, constituida en Bilbao en 1931 con la participación financiera del Banco Exterior, se integran los activos forestales (3.000 hectáreas) de los hermanos González Gorbeña con los terrenos adjudicados a Juan Aguirre Achútegui (9.500 hectáreas), presidente de la compañía ${ }^{12}$. Por su parte, PROHISCO, fundada en Madrid en 1932, pasa a explotar los recursos madereros procedentes de la concesión de 1.000 hectáreas adjudicada en octubre de 1929 a José Pereira Novas y las 2.000 hectáreas de terreno forestal otorgadas a Eugenio Escuredo y Lastra en junio de $1932^{13}$. Por último, a la Compañía de Maderas de Río Benito se incorpora como accionista Daniel Araoz, aportando al patrimonio de la sociedad dos terrenos de 1.200 y 2.000 hectáreas, adjudicados, respectivamente, en 1930 y $1933^{14}$.

La tercera fórmula de penetración está representada por empresas como COGUISA (Colonizadora de Guinea Continental) y ALENA (Compañía Nacional de Colonización Africana). La primera se constituye en Barcelona en octubre de 1929 después de que el adjudicatario original, Francisco Vives, traspase a los activos de la empresa la concesión de 5.000 hectáreas otorgada en 1928; pero también recurre a la adquisición en 1930 de una antigua compañía radicada en Bata, Alfonso Íñigo, con el fin de acelerar la puesta en

ten condicionantes históricos y normativos que maticen el carácter de "cifra redonda» de la superficie que se solicita, aunque ésta sí que se altera más tarde, una vez que se procede a restar la superficie reservada a los poblados indígenas que pudiese haber dentro de los límites solicitados.

9. AGA, cajas 81/6724, 81/6853, 81/6854; Gaceta de Madrid, 12/04/1927, 13/05/1927.

10. El acrónimo AGGOR proviene del apellido de las personas que fundan la empresa: Aguirre y Gorbeña.

11. Gaceta de Madrid, 12/06/1927, 05/09/1929, 10/10/1929.

12. AGA, cajas 81/6845, 81/6845; Gaceta de Madrid, 10/06/1930, 31/12/1930, 20/02/1932, 08/06/1932, 29/06/1932.

13. Gaceta de Madrid, 13/07/1929, 19/10/1929, 11/12/1931, 19/06/1932.

14. AGA, caja 81/6846; Gaceta de Madrid, 18/10/1931, 06/05/1933, 10/05/1933. 
marcha de COGUISA y reducir sus costes de explotación ${ }^{15}$. Ésta adquiere plantaciones, utillaje, factorías, viviendas y cupos de contratación de braceros en una operación sostenida en un $25 \%$ por la casa Wilhelm Gerkens \& Co., experta en la organización de negocios coloniales y a través de la cual COGUISA pasa a disponer de una delegación comercial en Hamburgo ${ }^{16}$.

Una estrategia análoga es la que adopta la que llega a convertirse en la mayor sociedad colonial radicada en este territorio: ALENA ${ }^{17}$. Con anterioridad a su constitución en 1929, tres de sus posteriores accionistas (Antonio Pérez López, Joaquín Carles Ferrer y Alfonso Pérez Andújar) solicitan y consiguen un continuo de concesiones de 28.500 hectáreas al norte de la colonia, en la frontera con Camerún (Río Campo). A ellas se les suma un año después otra de 2.500 hectáreas en Etembue, en el litoral entre Río Benito y Cabo San Juan ${ }^{18}$. En ese mismo momento, ALENA adquiere la sociedad Agrícola y Comercial de Bata, especializada desde unos años antes en el comercio de maderas ${ }^{19}$.

Si el negocio principal de esta firma es la extracción y la comercialización de la madera, sus intereses empresariales no se circunscriben exclusivamente a este sector. De hecho ALENA, al igual que otras entidades mercantiles, se sirve de las lucrativas oportunidades empresariales que brinda el hecho colonial y aprovecha el capital técnico, el personal y la organización mercantil de los que dispone en la colonia para desplegar su ámbito de influencia sobre un elenco mucho más diversificado de actividades.Y es que las empresas forestales operan en realidad como compañías coloniales: cuentan con plantaciones agrícolas dedicadas al cultivo de café, disponen de factorías comerciales, establecen acuerdos con los finqueros para la compra-venta de toda clase de productos, con-

\section{AGA, caja 81/6849.}

16. COGUISA (1931); AGA, caja 81/8151.

17. ALENA (1931).

18. AGA, cajas 81/6845, 81/6845, 81/6845; Gaceta de Madrid, 22/03/1928, 25/03/1928, 05/07/1928, 07/0/1928, 02/02/1930, 25/09/1930.

19. La fundación de ALENA es un exponente del interés de los capitales catalanes por el control de la economía maderera de la Guinea continental. Los principales puestos del consejo de administración de la empresa están ocupados en este momento por Carlos Maristany Benito, vicepresidente de ALENA y del Banco de Cataluña; Eduardo Recasens Mercader, director general del Banco de Cataluña; Eduardo Buxaderas de la Cantera, consejero de la Banca López Bru y del Banco Exterior, y gerente del Banco Hispano Colonial; y Ramón Albó Martí, presidente del Banco de Cataluña. Estos cuatro consejeros lo son a su vez del Banco de Crédito Local en cuyo consejo de administración figura también Alfredo Bauer (NúÑEZ RoMERo \& GoNZÁlez RUIZ, 2008). El consejo de administración de ALENA se completa con los nombres de Alfonso Pérez Andújar y Joaquín Carles Ferrer (consejeros delegados), Antonio Pérez López (vocal), Juan Capdevila Rovira (secretario) y José María Carreras Ferrer (director gerente) así como Adolfo y Blas Pérez Andújar que actúan como apoderados de la compañía (AGA, caja 81/ 6845). 
trolan la distribución de combustibles y lubricantes, operan como prestamistas, actúan como consignatarios de buques y organizan líneas de transporte marítimo con la metrópoli para la importación y exportación de todo tipo de bienes.

El negocio forestal se extiende a la metrópoli mediante el establecimiento de instalaciones industriales para la fabricación de tableros contrachapados. Es el caso de ALENA, que adquiere Manufacturas Valencianas del Okume y monta una nueva planta en el entorno del puerto de Barcelona, lo que le permite colocar sus propias maderas en el mercado nacional durante las coyunturas especialmente críticas que afectan al mercado de Hamburgo ${ }^{20}$. También el de la compañía catalana Jover y Graells, que, además de destacar por su empeño en dar a conocer entre los industriales las propiedades técnicas de las maderas guineanas e incrementar la demanda del mercado nacional, constituye en 1935 dos empresas domiciliadas en Barcelona: ASMACO (Aserraderos de Maderas Coloniales) y CAPA (Compañía Anónima de Productos Africanos), dedicadas al aserrado de maderas coloniales y la fabricación de chapas y tableros contrachapados ${ }^{21}$. Igualmente, la casa Izaguirre multiplica su cifra de negocio con la integración en el circuito productivo de la compañía de dos centros de transformación en España. Uno es la factoría de La Aeronáutica S.A., instalada en las proximidades de Bilbao para la fabricación de tableros contrachapados especiales para aeroplanos civiles y militares y automóviles; y otro, la empresa Chapas Finas de Madera, S.A., radicada también en Bilbao y dedicada a la contraventa de chapa, tablero contrachapado y maderas coloniales para ebanistería y carpintería ${ }^{22}$.

Por último, también cabe entender dentro de esta estrategia, la creación de la sociedad Tableros y Asientos de Madera, S.A. Promovida por ALENA, el capital social de esta empresa es suscrito al $50 \%$ entre ésta y un grupo de industriales que reúne con sus siete fábricas la mayor parte de la capacidad de producción instalada en España. Su objeto es la compra de ocume en troncos y su distribución entre los fabricantes asociados, pero también la venta unificada y exclusiva del tablero contrachapado, una operación con la que pretende apuntalar los intereses de los madereros coloniales y eliminar la competencia de otros fabricantes ${ }^{23}$.

El proceso de concentración de capitales industriales se verifica, asimismo, en la propia colonia con la cristalización de acuerdos de integración de las explotaciones foresta-

20. ALENA (1931).

21. Anuario Financiero y de Sociedades Anónimas de España, 1925, 1929, 1933.

22. Ibid.

23. ALENA (1936). 
les con el fin de aumentar su escala e intensificar el rendimiento de las inversiones efectuadas en ellas. Éste es el sentido de la operación de fusión de los activos de CAIGE y ALENA que tiene lugar en 1932 tras la difícil situación que atraviesa la primera debido a la suspensión de pagos de la casa Bauer en $1931^{24}$. ALENA adquiere casi la totalidad de las acciones de CAIGE y se compromete a garantizar el pago de la deuda de cerca de dos millones de pesetas que tenía con la Comisión Liquidadora de Bauer y Cía. ${ }^{25}$. Con esta operación, ALENA robustece su posición de dominio en el control de los recursos forestales del continente, incrementa sustancialmente su escala de producción y extiende su ámbito de influencia a una superficie equivalente a cerca de la mitad del bosque explotado en este período (Guerra \& Pascual, 2015).

Con una lógica semejante se puede entender la aparición de otros vínculos interempresariales. Es el caso de las compañías Vasco-Africana y Manyani. La primera explota a partir de 1932 la finca adjudicada en 1928 a Luis Sanginés y Renovales: una extensión de 5.000 hectáreas otorgada originalmente para desbosque y cultivos especiales de café y palmera de aceite y cuyo uso se transforma en foresta ${ }^{26}$; pero además pasa también a explotar, a través de Manyani, S. A., las 3.000 hectáreas de terrenos forestales adjudicados en 1928 a Guillermo Pelizaeus y Lanz, conde de Santa María de Sisla ${ }^{27}$.

\section{EL MODELO DE NEGOCIO FORESTAL: LA EXPLOTACIÓN EXTRACTIVA DE LA SELVA}

Durante esta etapa, la actividad forestal de las compañías concesionarias se desenvuelve en el marco de un sistema de aprovechamiento caracterizado por la ausencia de planes directores de explotación. El escenario de la producción está presidido por el interés inmediato por aprovechar la demanda de ocume que genera el mercado europeo y a esta finalidad se supedita cualquier otro planteamiento de explotación ordenada del bosque.

24. En 1932 al frente de la dirección general de CAIGE se encuentra Octavio Elorrieta (Montes e Industrias, noviembre de 1932). Elorrieta fue director general de Montes entre 1928 y 1930, y ocupó posteriormente la dirección del Instituto Forestal de Investigaciones y Experiencias (IFIE). Bauer y Cía. contaba con una fuerte participación en la Compañía Iberoamericana de Publicaciones (CIAP), sociedad que experimenta un gran proceso de expansión sobre la base de un complejo entramado financiero. El sobreendeudamiento de esta sociedad termina por hacerla quebrar, lo que finalmente provoca la ruina y la desaparición de la casa Bauer (LÓPEZ-MORELL, 2005).

25. CDMH, fondo Político-Social-Documentación particular, caja 192.

26. AGA, cajas 81/6425, 81/6848; Gaceta de Madrid, 27/04/1928.

27. Gaceta de Madrid, 01/01/1928, 19/04/1928. 
Debido a un desconocimiento generalizado del terreno y a la inexistencia de cartografía del territorio colonial (Guerra \& Pascual, 2015), la delimitación de las superficies adjudicadas en las subastas es siempre imprecisa y, en consecuencia, es fuente de tensiones entre el concesionario y la administración colonial, lo que genera también conflictos entre las propias compañías forestales y los titulares de las fincas agrícolas. A las dificultades para establecer los límites formales de la concesión, se une la incapacidad técnica y, en cierto modo, el desinterés de las compañías por dedicar tiempo y recursos para realizar algún tipo de aproximación certera sobre la riqueza de las manchas de ocume susceptibles de extracción. De este modo, los problemas que acompañan a la delimitación de las concesiones y la carencia de recuentos previos que permitan disponer de un inventario básico de los ejemplares forestales determinan una forma de explotación que, por una parte, adolece de múltiples ineficacias productivas y, por otra, favorece el abuso sobre los derechos de aprovechamiento de la selva.

En este sentido, son elocuentes las observaciones realizadas por el ingeniero jefe del Servicio Forestal de la colonia en el informe remitido en 1930 a la Dirección General de Marruecos y Colonias, tras los trabajos de inspección realizados para conocer el estado de las concesiones. En él se refleja que la compañía Izaguirre se encuentra explotando su concesión sin haber sido previamente delimitada o que SOCOGUI está apeando ejemplares de ocume en el terreno de reserva de la concesión sin autorización de la administración colonial. También se denuncia la proliferación de irregularidades entre las fincas agrícolas que, al contar con una superficie inferior a 100 hectáreas, son otorgadas directamente por el Gobierno General de Guinea. Entre 1927 y 1930 éstas suman en el continente 7.100 hectáreas, de las cuales, sólo 2.200 están destinadas realmente a cultivos, mientras que el resto se dedican al aprovechamiento forestal. Y es que la mayor rapidez en los procedimientos de concesión, por no requerir subasta, encubre como agrícolas un amplio número de fincas que son rápidamente esquilmadas de su riqueza maderable entrando a su vez en colisión con las concesiones forestales que, en numerosas ocasiones, incorporan en su delimitación manchas de ocume que ya han sido explotadas ${ }^{28}$.

Son frecuentes igualmente las referencias documentales a los problemas que genera el desconocimiento por parte de las compañías forestales de los recursos maderables de sus propias concesiones y el desarrollo de los trabajos de explotación sin un programa establecido. Así se pone de manifiesto en la notificación remitida en 1932 al Banco Exterior por un informante comisionado por la entidad financiera, que constata la imposibilidad de comprobar la veracidad de las reservas de ocume que ALENA declara como activos en sus concesiones en Río Campo, debido a que el personal de la compañía no

28. AGA, caja $81 / 6856$. 
ha realizado una exploración completa del terreno ni se ha procedido a confeccionar un recuento fiable de los ejemplares comercializables ${ }^{29}$.

Éste es uno de los aspectos clave para entender la forma en que se organiza la producción de madera, el desencuentro que a menudo se origina entre el discurso de la administración forestal colonial y el de las compañías concesionarias, así como las contradicciones de las propias empresas en la salvaguarda de los intereses del negocio forestal.

\subsection{La mecanización de las explotaciones y las inversiones en capital fijo}

El terreno delimitado por la concesión forestal se organiza conforme a las lógicas de un espacio productor en el que tiene lugar la acumulación progresiva de capital técnico y la concentración de mano de obra nativa. Las operaciones previas a la explotación requieren el trazado de las vías principales de saca (pistas o ferrocarril maderero). Las compañías coloniales optan por el ferrocarril como infraestructura básica sobre la que organizar el movimiento de la madera. El transporte por carretera resulta en principio menos exigente, tanto en las inversiones de acondicionamiento como en la disponibilidad de medios técnicos; sin embargo, sólo se emplea de forma complementaria durante la estación seca, ya que su utilización como medio permanente requiere obras de mantenimiento que los concesionarios no están dispuestos a asumir, alegando que su coste no queda compensado por el valor comercial de la madera. En consecuencia, la organización de los trazados ferroviarios se convierte en un factor esencial en el control de la riqueza forestal, y los recursos destinados a este fin engrosan el capítulo principal en la inversión de capital fijo. El tipo de material que se emplea es el que ofrece mayores ventajas para la rentabilidad del negocio, tanto por su coste como por su facilidad de traslado cuando se cambia la zona de explotación. Sin embargo, las compañías forestales trabajan sin un programa escalonado de saca que prevea la longitud y la dirección concreta que han de seguir los trazados ferroviarios debido al escaso conocimiento sobre el emplazamiento de las manchas de ocume. Así, en determinados momentos el sistema de trabajo se resiente de un elevado grado de improvisación que provoca la inversión de recursos en la explanación de terrenos que resultan inadecuados o el avance de las operaciones forestales a través de la concesión dejando a su paso ejemplares de ocume sin explotar (Capdevielle, 1947).

El ferrocarril no tiene uniformidad de vía, aunque predomina la vía métrica, y su tracción se realiza con locomotoras de vapor o motor. A lo largo de este período, se impone

29. CDMH, fondo Político-Social-Documentación particular, caja 192. 
la utilización de la locomotora de explosión, mientras que el vapor, empleado por las primeras compañías concesionarias, queda relegado a un segundo plano, lo que pone de manifiesto la preferencia por la instalación de tendidos ferroviarios secundarios de carácter provisional y susceptibles de ser trasladados con facilidad, una vez agotada la riqueza maderable de un sector de la concesión. Este modo de operar provoca en no pocas ocasiones el recelo de los servicios forestales de la colonia, que consideran lesivo para los intereses del Estado la descompensación entre los beneficios que las compañías obtienen de la explotación del bosque y la escasa inversión que realizan en la mejora de las infraestructuras ${ }^{30}$. Ciertamente, los ferrocarriles forestales no llegan a componer una verdadera red de uso público, ya que funcionan como líneas independientes, cuyo recorrido finaliza en los muelles de playas y ríos navegables, lo que responde de forma exclusiva a los intereses de la compañías (Ramírez Copeiro del Villar, 2007).

A esta finalidad se orienta también la temprana introducción en la Guinea continental -en comparación con las explotaciones gabonesas- de maquinaria de gran potencia para realizar algunos de los trabajos forestales. Así, en 1929 la compañía CAIGE ya incorpora el tractor de oruga (Carterpillar) y seguidamente otros madereros reproducen este sistema de saca, lo que permite ampliar la zona de explotación y acelerar notablemente el ritmo de tala. Ciertamente no todas las compañías cuentan con medios técnicos similares y su capacidad de inversión en el negocio forestal es desigual. En cualquier caso, en el proceso de aprovechamiento de los recursos forestales se asiste a una importante dotación de capital técnico destinado a extraer de forma intensiva la riqueza maderable. Además, la acumulación de material mecánico y su rápido desgaste en los trabajos forestales exigen al mismo tiempo la existencia de un gran stock de piezas de repuesto y mantenimiento del utillaje, lo que supone la concentración de un elevado volumen de capital inmovilizado. Como puede observarse en el Cuadro 1, que expresa el valor del material de explotación adquirido por las empresas madereras, las inversiones productivas de mayor entidad corresponden a los costes de instalación de los ferrocarriles, cuyo tendido en la Guinea continental se extiende por una longitud de unos 120 kilómetros hasta finales de los años treinta.

No obstante, es importante reseñar también que la mecanización de las explotaciones no siempre responde a principios de racionalidad y eficacia productiva. Así se constata en el informe elaborado por el Servicio Forestal en 1942, en el que se advierte que compañías como Vasco-Africana y Manyani han adquirido en los años precedentes un número de tractores por encima de sus necesidades, ya que carecen de vías y medios de tracción acordes con la capacidad de movimiento de madera que ofrece esa maquinaria. Tam-

30. AGA, caja $81 / 6856$. 
bién esa falta de equilibrio armónico en la adquisición de medios técnicos es común entre las concesiones de menor entidad, ya que los gastos fijos son proporcionalmente muy elevados cuando se trabaja en superficies inferiores a 5.000 hectáreas $^{31}$.

\section{CUADRO 1}

Material de explotaciones forestales, 1942 (en miles de pesetas)

\begin{tabular}{|c|c|c|c|c|c|c|c|c|c|}
\hline Sociedad & Material & Vías & Tractores & Camiones & Elementos & Materiales de transporte & e Total & $\%$ & Ptas./ha \\
\hline & ferroviario & & y equipos & & auxiliares & fluvial y marítimo & & & \\
\hline ALENA & 824 & 2.600 & 522 & 220 & 50 & 170 & 4.386 & 24,1 & 141,5 \\
\hline CAIGE & 75 & 1.025 & 580 & & 120 & & 1.800 & 9,9 & 87,4 \\
\hline Izaguirre y Cía. & 324 & 1.600 & 666 & & 52,5 & 680 & $3.322,5$ & 18,2 & 184,6 \\
\hline AGGOR & 254 & 995 & 536 & 25 & 64 & 247 & 2.121 & 11,6 & 169,7 \\
\hline Vasco-Africana & 234 & 1.050 & 672 & & 14 & 100 & $2.070,5$ & 11,4 & 414,1 \\
\hline Jover y Graells & 521 & 715 & 338 & 60 & 32 & 236 & 1.902 & 10,4 & 613,5 \\
\hline Manyani & 113 & 240 & 672 & & 14 & 150 & 1.189 & 6,5 & 396,3 \\
\hline SOCOGUI & 204 & 337 & & 90 & 35 & & 666,5 & 3,7 & 133,3 \\
\hline Daniel Araoz & 48 & 106 & 252 & & & 20 & 426 & 2,3 & 133,1 \\
\hline PROHISCO & 87 & 137,5 & 110 & & 8,5 & & 343 & 1,9 & 114,3 \\
\hline Total & $2.684,5$ & 8.806 & 4.348 & 395 & 390 & 1.603 & $18.226,5$ & 100,0 & \\
\hline
\end{tabular}

Fuente: elaboración propia a partir de AGA, caja 81/8150, 1942.

Del mismo modo, a medida que las concesiones van siendo vaciadas de sus principales reservas de ocume, las anomalías en la estructura de los costes se extienden al conjunto de las compañías forestales, acuciadas por la necesidad de redimensionar su escala de producción como garantía de supervivencia en el negocio forestal. Tal es lo que sucede a partir de 1930 cuando se acumulan las demandas de ampliación de las concesiones ante la Dirección General de Marruecos y Colonias. Invariablemente las compañías exhiben en sus escritos de solicitud abultadas cifras de inversión en medios técnicos, cuya amortización se encuentra en entredicho si no se atienden sus requerimientos. Así lo atestigua la documentación remitida por AGGOR en 1934, en la que se realiza un inventario de su capital técnico por valor de 1,5 millones de pesetas ${ }^{32}$. De ese mismo año es la enumeración del material de explotación y de transporte fluvial de Jover y Graells ${ }^{33}$.

Dos años antes, ALENA había solicitado también la ampliación de una de sus concesiones con argumentos casi idénticos, referidos a la imposibilidad de mantener el ren-

31. AGA, caja $81 / 8150$.

32. AGA, caja $81 / 6854$.

33. AGA, caja $81 / 6853$. 
dimiento económico del capital fijo instalado ${ }^{34}$. La compañía advierte del agotamiento inminente del ocume en su concesión y del problema de abastecimiento de madera que esto lleva consigo hasta que concluyan los trabajos de acondicionamiento del tendido ferroviario previsto en los terrenos forestales adjudicados en Río Campo. En tal sentido, alude a la imposibilidad de proseguir la explotación con los métodos de trabajo que se requieren para competir con las casas productoras del Gabón francés, donde la dimensión media de las concesiones es mucho mayor, y plantea la necesidad de promover la concentración de las concesiones forestales para superar esta distorsión en la estructura de los costes de producción ${ }^{35}$. De hecho, ALENA atraviesa entonces por graves dificultades provocadas por la insuficiencia de capital, tanto para mantener sus inversiones como para asegurar la formación del capital circulante necesario para seguir impulsando su actividad empresarial en la colonia. Los problemas de integración y la discrepancia de intereses entre la actividad de la planta de contrachapado de Barcelona y la producción de ocume en la Guinea continental generan un déficit en la tesorería del grupo que obliga al diseño de un plan de reorganización de la empresa que incluye la apremiante necesidad de incrementar las reservas forestales disponibles y el aprovechamiento integral de las existencias maderables ${ }^{36}$.

En suma, las compañías concesionarias esgrimen el valor del capital fijo instalado no sólo como elemento clave para defender sus intereses y disponer de nuevas reservas que rentabilicen el esfuerzo inversor realizado, sino también como evidencia para refutar la razón que justifica la suspensión del otorgamiento de nuevos lotes de terreno decretada en 1930, esto es, la escasez de braceros ${ }^{37}$.Y es que, si los recursos de capital técnico y capital circulante son determinantes para mantener la explotación extractiva de la selva, la provisión de mano de obra representa otro capítulo esencial en el funcionamiento de la economía forestal.

\subsection{La fuerza de trabajo como factor de producción en el negocio forestal}

Para las compañías que operan en el continente, es un requisito primordial contar con grandes brigadas de braceros para asegurarse el aprovechamiento de las reservas maderables. De hecho, en la conformación de la economía colonial, el acaparamiento de la

\section{AGA, caja $81 / 6845$.}

35. CDMH, fondo Político-Social-Documentación particular, caja 192; AGA, caja 81/6845.

36. Informe al Consejo de Administración de ALENA, 1 de septiembre de 1932; CDMH, fondo Político-Social-Documentación particular, caja 192.

37. Real Orden de 3 de mayo de 1930. 
mano de obra es un instrumento fundamental, cuyo control efectivo determina la implantación de un modo de regulación no exento de tensiones permanentes debido a la necesidad de mantener el orden social. Ante la escasez de mano de obra nativa disponible y su creciente demanda por parte de los colonos agrícolas y forestales, se arbitra el establecimiento de un sistema adoptado en 1926 por la Junta de Autoridades en Santa Isabel, que asigna un cupo de trabajadores a los concesionarios en función de la superficie de los terrenos otorgados ${ }^{38}$. En este contexto, la implantación de sistemas de reclutamiento forzoso y la llegada periódica de braceros procedentes de las colonias inglesas y francesas del África occidental (fundamentalmente nigerianos) compone una provisión de trabajadores sobre los que se descarga con mayor dureza la violencia de la dominación colonial (Campos, 2005; Nerín, 2010).

\section{CUADRO 2}

Procedencia de los braceros al servicio de las fincas agrícolas y explotaciones forestales, 1941

\begin{tabular}{|c|c|c|c|c|c|c|c|c|c|}
\hline \multirow[t]{3}{*}{ Tipo de explotación } & \multicolumn{6}{|c|}{ Procedencia } & \multicolumn{3}{|c|}{ Total } \\
\hline & \multicolumn{2}{|c|}{ Guinea Española } & \multicolumn{2}{|c|}{$\begin{array}{c}\text { Colonias inglesas (Camerún } \\
\text { británico y Nigeria) }\end{array}$} & \multicolumn{2}{|c|}{$\begin{array}{c}\text { Colonias francesas (Gabón } \\
\text { y Camerún francés) }\end{array}$} & \multirow{2}{*}{$\begin{array}{c}\text { Total } \\
\% \\
\end{array}$} & \multirow[b]{2}{*}{ Número } & \multirow[b]{2}{*}{$\%$} \\
\hline & Número & $\%$ & Número & $\%$ & Número & $\%$ & & & \\
\hline Agrícolas & 4.121 & 76 & 1.181 & 22 & 146 & 3 & 100 & 5.448 & 73 \\
\hline Forestales & 1.738 & 86 & 260 & 13 & 29 & 1 & 100 & 2.027 & 27 \\
\hline Total & 5.859 & 79 & 1.441 & 19 & 175 & 2 & 100 & 7.475 & 100 \\
\hline
\end{tabular}

Fuente: elaboración propia a partir de Perpiñá (1945: 119).

La presencia de estos trabajadores es significativa en las fincas agrícolas (que requieren mucha más mano de obra), donde la proporción de estos colectivos alcanza el $25 \%$. Sin embargo, en las concesiones forestales, el recurso a los braceros es bastante menor, y, generalmente, queda circunscrito a los trabajos de apertura de caminos y tendido de vías férreas, así como a las operaciones de explanación, que son las que requieren mayor fuerza de trabajo. Al finalizar esta etapa, este grupo de trabajadores representa el 14\% de la mano de obra contratada en las concesiones forestales, tal y como se constata en el Cuadro 2, elaborado a partir de los datos proporcionados por la Subdelegación del Trabajo en la Guinea Española. Aunque las cifras corresponden al año 1941, el número total de braceros al servicio de las explotaciones forestales (2.027) no difiere mucho de la estadística elaborada en 1938 por el Subgobierno General de Bata (2.139). En esta última (Cuadro 3) se reflejan además las diferencias de capacidad en el reclutamiento de mano de obra na- 
tiva, en función de la desigual entidad de unas compañías y otras, al tiempo que se pone de manifiesto cómo, en sólo unos años, se produce un notable incremento en el rendimiento del trabajo, ya que, si en 1935 la cifra de madera cortada se sitúa en 35 toneladas por trabajador, esta relación prácticamente se duplica en 1937. Sin duda, la paulatina mecanización de las explotaciones favorece el aumento relativo del ritmo de producción, pero a ello también contribuye el progresivo endurecimiento de las condiciones de trabajo imperantes en las concesiones forestales.

\section{CUADRO 3}

Contratación de braceros en las concesiones forestales

\begin{tabular}{lrrr}
\hline Concesiones & $\mathbf{1 9 3 5}$ & $\mathbf{1 9 3 6}$ & $\mathbf{1 9 3 7}$ \\
\hline ALENA & 1.222 & 315 & 88 \\
Izaguirre & 194 & 222 & 288 \\
AGGOR & 191 & 148 & 152 \\
Jover y Graells & 162 & 52 & 54 \\
PROHISCO & 25 & 67 & 57 \\
A. Schmidt & 20 & 18 & 16 \\
SOCOGUI & 46 & 249 & 13 \\
Vasco-Africana & 186 & 129 & 101 \\
Manyani & 0 & 44 & 42 \\
COGUISA & 93 & 31 & 9 \\
Total & 2.139 & 1.275 & 820 \\
Madera cortada Tm & 74.790 & 77.282 & 55.883 \\
Tm por bracero & 35,0 & 60,6 & 68,2 \\
\hline * Gobierno General de los Territorios Españoles del Golfo de Guinea. \\
Negociado de Estadística. Resúmenes de los años 1942 y 1943. Ma- \\
drid, 1945
\end{tabular}

Fuente: AGA, caja 81/8126, Sindicato Maderero, 1938.

De hecho, la vulneración sistemática de lo dispuesto en las normas de regulación del trabajo indígena constituye la tónica dominante entre los patronos. Así lo verifica la documentación referida a las condiciones en las que se desenvuelve el trabajo del personal nativo al servicio de las explotaciones forestales, entre las que se cita a Jover y Graells, AGGOR y PROHISCO. Las visitas de inspección de las concesiones ponen al descubierto que la gran mayoría de sus titulares incumplen las obligaciones de manutención con los trabajadores en la asignación de raciones alimenticias y prendas de vestir, someten a los nativos a interminables jornadas de trabajo y a castigos corporales, $\mathrm{y}$ hacinan a los trabajadores en viviendas precarias y antihigiénicas que ellos mismos deben levantar. A estas penosas condiciones se suman las penalizaciones antirreglamentarias en el salario por no completar el destajo ordenado o por faltas al trabajo por enfermedad, lo que además 
lleva consigo la pérdida de la ración alimenticia y la prórroga forzada del contrato de trabajo $^{39}$.

Las compañías forestales se empeñan, no obstante, en mostrar una realidad bien distinta y, en su discurso ante la Administración sobre su «inestimable» contribución al progreso del proyecto colonial invariablemente aluden a la excelente organización de las brigadas de braceros, al estricto cumplimiento de los compromisos salariales, al suministro de raciones que superan las impuestas por el reglamento, a la disponibilidad de poblados higiénicos para el alojamiento de los braceros o a la calidad de los servicios sanitarios acondicionados para su atención, en razón de lo cual el peso del coste de la mano de obra en los gastos de explotación es muy elevado ${ }^{40}$.

De nuevo en este aspecto, la documentación elaborada por los servicios forestales permite contraponer una visión diferenciada que hace hincapié, en cambio, en el sobredimensionamiento de las plantillas de personal europeo y en el peso desproporcionado de su retribución en la estructura de los costes de explotación, habida cuenta de su escasa cualificación y de la carencia de conocimientos técnicos sobre los sistemas de aprovechamiento del bosque. La ausencia de técnicos competentes en las explotaciones forestales parece generalizada entre las compañías, salvo contadas excepciones, como es el caso de ALENA, única empresa colonial que cuenta con un ingeniero agrónomo al frente de sus servicios técnicos ${ }^{41}$.Y todo ello no sólo redunda en una estructura desequilibrada de los costes, sino también en la inferior calidad de las maderas guineanas frente a los productores franceses de Gabón con los cuales habrá de competir en el mercado europeo ${ }^{42}$.

\section{LA INSERCIÓN INTERNACIONAL DE LA PRODUCCIÓN FORESTAL EN LOS MERCADOS DEL NORTE DE EUROPA}

En consonancia con el imaginario construido en torno a la magnificencia de la selva, durante las dos primeras décadas del siglo xx toma forma un discurso que pone el acento en las extraordinarias expectativas de los recursos forestales de la colonia para generar una importante corriente de madera hacia la metrópoli. La disponibilidad de estas materias primas permitiría contrarrestar, y paulatinamente eliminar, la dependencia de las importaciones de Cuba, México y Estados Unidos, y adicionalmente impulsar el desarro-

\footnotetext{
39. AGA, caja $81 / 6261$.

40. AGA, cajas $81 / 6846,81 / 6853,81 / 6845$.

41. AGA, caja $81 / 6846$.

42. AGA, cajas $81 / 6856,81 / 6845$.
} 
llo de una industria nacional capaz de competir con las manufacturas europeas ${ }^{43}$. Sin embargo, no es el mercado metropolitano el destino prioritario de la madera procedente de la Guinea continental durante esta etapa, sino que la producción del ocume de la colonia española pronto se incorpora a las grandes corrientes comerciales organizadas en torno al mercado alemán.

La potente industria del tablero contrachapado sitúa a Alemania en una posición dominante en el mercado mundial, de manera que el funcionamiento de este mercado en sus aspectos básicos, la organización de los agentes económicos que intervienen en las transacciones internacionales de ocume, el trazado de las rutas comerciales, así como los precios están enteramente condicionados por el comportamiento de la demanda alemana. En tal sentido, los productores forestales españoles tratan de aprovechar el dinamismo de estos circuitos de distribución, controlados por las compañías francesas que abastecen de ocume al mercado europeo. En este escenario, la creciente integración del ocume español en los grandes flujos comerciales es, sin lugar a dudas, muy relevante, ya que, en cierto modo, es capaz de romper el monopolio detentado por los exportadores franceses y afianzarse paulatinamente en un mercado complejo y muy sensible a las coyunturas y a la inestabilidad de la economía alemana durante estos años.

La evolución del mercado europeo de ocume entre 1926 y 1936 muestra, en efecto, un proceso expansivo, pero también se halla sometida a importantes fluctuaciones que dibujan tres ciclos diferenciados de corta duración (Gráfico 1). El primero (desde los años veinte hasta mediados del año 1930) se caracteriza por una tendencia alcista y por la firmeza en el comportamiento de la demanda. En 1926 las llegadas de ocume a los puertos europeos se cifran en 95.000 toneladas, y experimentan una fuerte progresión hasta alcanzar cerca de 250.000 toneladas en 1930. Esta favorable coyuntura imprime un importante ritmo de crecimiento a las exportaciones procedentes de la Guinea continental, que multiplican por 2,5 su presencia en los mercados del norte de Europa. Coincidiendo con la intensificación de la producción forestal en la colonia, las compañías españolas entran con fuerza en estos circuitos comerciales incrementando el suministro de ocume de 15.000 a 38.000 toneladas, aunque la proporción de madera española en el cómputo total de transacciones (el 12\% de promedio) se mantiene en niveles similares durante este período debido al notable aumento de descargas en los puertos europeos de grandes partidas de ocume procedentes de la colonia francesa de Gabón.

La inflexión puntal que interrumpe el crecimiento de la demanda de ocume en 1929 se convierte a partir de septiembre de 1930 en una brusca regresión que se extiende hasta

43. AGA, caja $81 / 6410$.

Historia Agraria, 72 • Agosto 2017 • pp. 135-166 
1933. Se trata de un ciclo de graves perturbaciones derivadas de los efectos especialmente virulentos de la crisis económica en Alemania. La ralentización generalizada de la actividad industrial, las restricciones de crédito a las empresas que imponen las entidades financieras y la paralización de numerosas fábricas de tableros provocan una gran inseguridad y una acusada atonía en el mercado del ocume. Esta situación provoca una sobredotación de la oferta que origina una importante acumulación de stocks almacenados en los puertos. Con el fin de contrarrestar la caída de los precios y tratar de aminorar los excedentes, se recurre a la derivación de cargamentos completos hacia los puertos franceses de Le Havre y Rouen, lo que desemboca, a su vez, en una saturación del mercado francés.

\section{GRÁFICO 1}

Madera exportada con destino al mercado alemán (1926-1935) 250.000

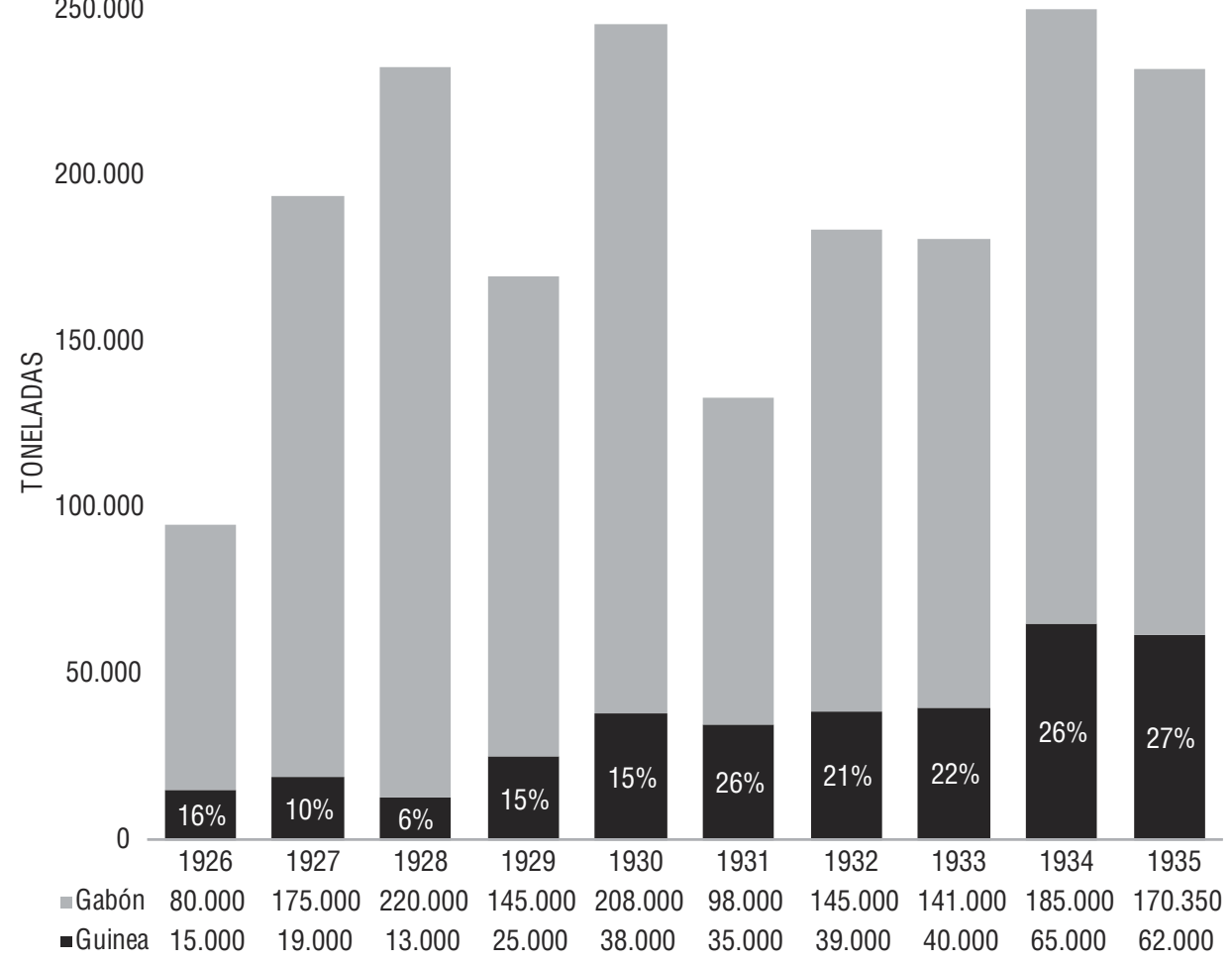

Fuente: elaboración propia a partir de AGA, diversos legajos.

En este escenario crítico, y con objeto de evitar una caída aún más pronunciada de los precios y recuperar la rentabilidad del negocio forestal, el Ministerio Colonial francés decreta sucesivas restricciones en la producción gabonesa y en el volumen de los embar- 
ques, lo que reduce drásticamente el suministro y logra una cierta estabilización del mercado de Hamburgo. Un mercado en el que las compañías forestales españolas se acreditan y consolidan gradualmente su posición, al producirse mejoras en la calidad de las maderas. También la depreciación de la peseta favorece las operaciones de exportación de ocume, que pasa de 35.000 toneladas en 1931 a 40.000 toneladas en 1933. No obstante, la inestabilidad de los mercados europeos empuja a los madereros coloniales a ampliar el foco de sus intereses comerciales incorporando el horizonte del mercado metropolitano y planteando la conveniencia de difundir en España las cualidades y las aplicaciones técnicas del ocume y de adoptar las medidas necesarias para impulsar el desarrollo de una industria nacional de contrachapado, capaz de absorber volúmenes progresivamente mayores de maderas tropicales. Pese a ello, el consumo nacional de esta madera permanecerá todavía en niveles muy bajos, en consonancia con el limitado desarrollo de la industria del tablero. Esto significa que, a lo largo del decenio 1926-1936, el mercado nacional tan sólo es capaz de absorber un tercio de la producción total de ocume de la colonia, que entra en la Península fundamentalmente a través del puerto de Valencia.

\section{GRÁFICO 2}

Exportaciones de ocume de las compañías forestales españolas (1934)

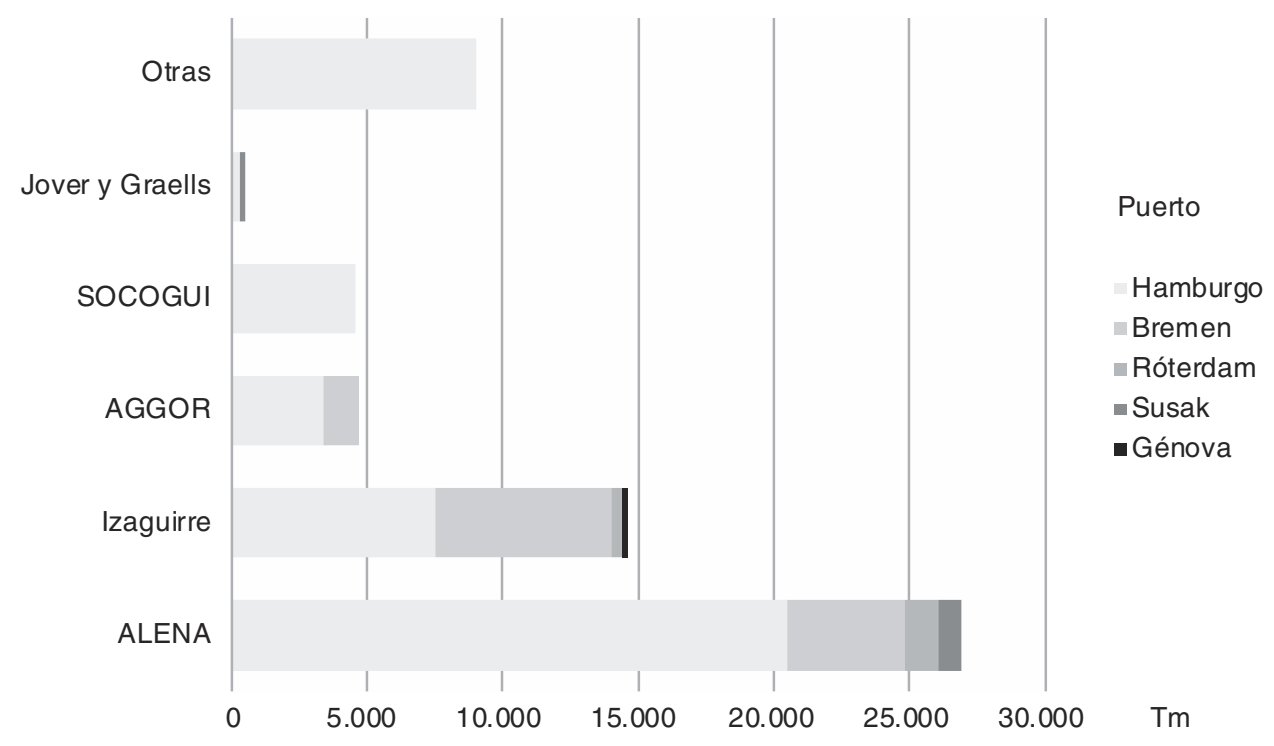

Fuente: elaboración propia a partir de AGA, diversos legajos.

El abastecimiento de la demanda alemana todavía permite a los productores españoles aprovechar las oportunidades que brinda este mercado, mantener durante unos años su 
presencia en los circuitos europeos de comercialización del ocume y acelerar el ritmo de exportación hasta superar las 60.000 toneladas en 1934 y 1935. Los datos reflejados en el Gráfico 2 cuantifican los desembarcos efectuados por las compañías forestales en los principales puertos europeos en el año 1934 y en él se aprecia sobre todo el potencial exportador de las compañías ALENA e Izaguirre, que conjuntamente aglutinan cerca del $70 \%$ de las transacciones del ocume originario de la colonia.

\section{GRÁFICO 3}

\section{Cotización del ocume en el mercado de Hamburgo (mayo de 1932-abril de 1936)} 700

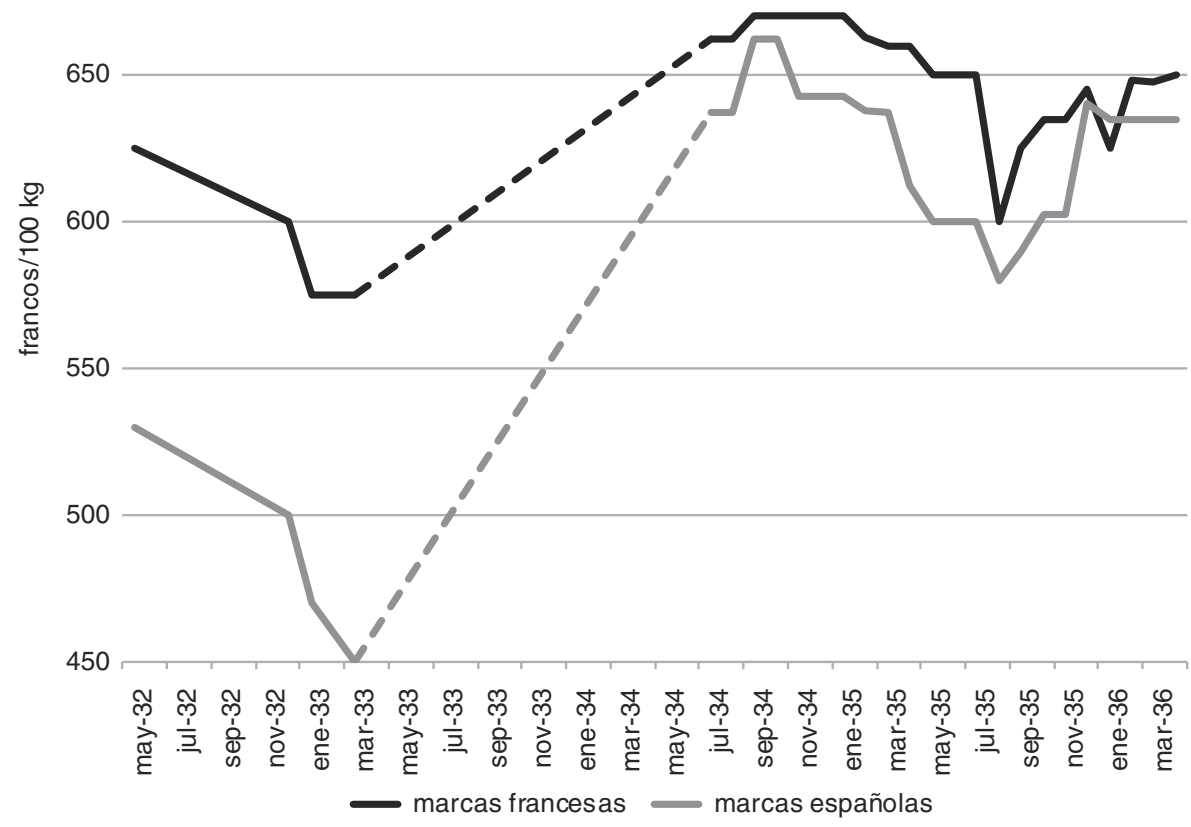

Fuente: elaboración propia a partir de AGA 81/6864 (Boletines mensuales sobre el mercado de madera de África Occidental. J.K. Müller \& Sohn. A. G.)

Tal y como puede observarse en el Gráfico 3, a lo largo de este último ciclo se logra una recuperación y ligera estabilización de los mercados, sacudidos, no obstante, por intensas fluctuaciones de los precios y coyunturales situaciones críticas derivadas de las dificultades para la transferencia de divisas y las restricciones de pagos impuestas por las autoridades alemanas. Las tensiones se acrecientan o se alivian alternativamente en razón de la marcha de las negociaciones para la ratificación de sendos tratados comerciales franco-alemán e hispano-alemán de manera que, a medida que los acuerdos se 
renuevan, se obtienen permisos de pago para las importaciones de madera francesa o española ${ }^{44}$.

En suma, el papel de las compañías forestales españolas en el aprovisionamiento de la demanda europea conoce durante la etapa 1926-1936 un notable dinamismo y una fuerte proyección a través de la cual se logra duplicar la cuota de mercado: el ocume originario de la colonia pasa así de representar el $12 \%$ del total comercializado en las transacciones internacionales entre 1926 y 1930 al $24 \%$ entre 1931 y 1936, si bien la cotización de las primeras marcas españolas se mantiene siempre por debajo de las francesas debido a su inferior calidad. La intensificación y mecanización de la producción y la expansión de la superficie forestal explotada consolidan definitivamente el perfil exportador de la Guinea continental, y la madera se convierte en el artículo de exportación más relevante de la colonia al concentrar más del $70 \%$ del valor de los productos comercializables.

Con todo, y pese a este considerable impulso, los flujos comerciales de ocume procedente de la colonia española no dejan de ocupar una posición secundaria en su capacidad de suministro a la industria europea, que durante la etapa 1926-1936 genera una demanda agregada superior a los dos millones de toneladas. De esta cifra, apenas el $20 \%$ corresponde a la producción forestal guineana, un sector que carece de la escala suficiente y las infraestructuras de comercialización adecuadas como para enfrentar con mayor vigor la competencia francesa.

Respecto de la escala de producción, tanto la entidad empresarial de las compañías españolas como la dimensión de las explotaciones forestales hacen que la competitividad de los recursos forestales guineanos en el mercado internacional se mantenga en niveles comparativamente bajos frente a la potencia que despliegan las grandes empresas concesionarias del Gabón francés. Por otra parte, la debilidad de la industria naviera española y su escaso desarrollo en el sector del transporte marítimo internacional constituyen también factores limitativos que se ponen de manifiesto muy tempranamente. Desde los primeros años veinte, los exportadores radicados en la colonia son conscientes de las difi-

44. Durante los años precedentes a la Guerra Civil en España se había mantenido un elevado nivel de importaciones que mermó considerablemente sus divisas y obligó a la regulación de las modalidades de pago a través del Centro Oficial de Contratación de Moneda. Entre estas modalidades se encuentran las cuentas clearing, que ya se habían acordado entre Alemania y España (TASCón, 2009). A través de este acuerdo, las autoridades monetarias de ambos países se comprometen a centralizar los pagos originados en las operaciones comerciales compensando cada cierto tiempo los saldos resultantes y permitiendo así minimizar el uso de divisas. 
cultades que plantea la ausencia de líneas regulares de transporte de mercancías, las deficiencias del servicio interinsular, la carestía de los fletes y la inexistencia de buques madereros nacionales de gran tonelaje. Los vapores que prestan servicio no están acondicionados para la carga y la estiba de grandes trozas y la limitada capacidad de sus bodegas obliga a transportar mercancías heterogéneas que frecuentemente llegan en mal estado a sus consignatarios ${ }^{45}$. Hasta la entrada en servicio en 1931 de la línea de la Compañía Naviera Amaya de Bilbao, sólo la Trasmediterránea realiza el transporte de madera. Sin embargo, esta compañía sólo cubre las rutas que conectan Bata, Río Benito y Kogo con los puertos de la metrópoli ${ }^{46}$. Por tanto, los exportadores de ocume recurren a los servicios de las grandes compañías navieras europeas, cuyas flotas pasan así a monopolizar el tráfico de la Guinea española. Fundamentalmente son la alemana Woermann Linie AG, la holandesa Holland West Africa Line, la francesa Delmas y la italiana Navegazione Libera Triestina las que, a través de las rutas marítimas que recorren los principales puertos de las colonias inglesas, francesas y alemana del África occidental (Lagos, Sekondi-Takoradi, Libreville, Port Gentil, Mayumba o Duala), realizan el desembarco de la madera en los puertos de Hamburgo, Bremen y Róterdam, a través de los cuales se importa prácticamente la totalidad del ocume destinado a la industria alemana (Gráfico 4) ${ }^{47}$.

La fuerza de estos grandes armadores y el control que ejercen sobre el tráfico marítimo de las colonias de la costa occidental africana se dejan sentir también en las dificultades que encuentra la Naviera Amaya para operar en los puertos europeos. Como se ha señalado anteriormente, en 1931 la naviera pone en servicio una nueva línea regular de transporte de mercancías entre el continente y los puertos españoles, franceses y alemanes, especializándose en las complejas operaciones de carga que tienen lugar en las playas del continente. La ausencia de infraestructuras portuarias obliga a transportar las balsas desde los ríos al costado de los buques (fondeados generalmente a dos o tres millas de distancia) y, al ser cargadas al vapor, se producen grandes pérdidas de madera. La naviera española consigue dominar este tipo de tráfico y reducir la proporción de pérdidas, sin embargo, no es capaz de competir con el precio de los fletes de los armadores internacionales para situar las mercancías en los puertos europeos y se ve obligada a reducir, en consecuencia, la regularidad de estas líneas hasta circunscribirse casi de forma exclu-

45. AGA, caja $81 / 6410$.

46. AGA, caja 81/8152.

47. CDMH, fondo Político-Social-Documentación particular, caja 192, Blanco Elola, A., «Informe sobre las comunicaciones marítimas entre España y sus Posesiones del Golfo de Guinea", Madrid, 10/09/1932; Archivo Nacional de Cataluña (ANC), fondo Casa de la Guinea española, fondo 257 1, fondos documentales, caja 1, Cámara agrícola de Fernando Póo. 
siva al tráfico con la Península ${ }^{48}$. De hecho, como puede comprobarse en el Gráfico 5, más del $80 \%$ de los cargamentos de ocume que se embarcan en Bata, Río Benito y Kogo en 1933 con destino a puertos alemanes y españoles lo hacen en buques madereros de pabellón extranjero.

\section{GRÁFICO 4}

\section{Distribución de la madera desembarcada en los puertos europeos} (valores agregados desde julio de 1934 hasta abril de 1936)

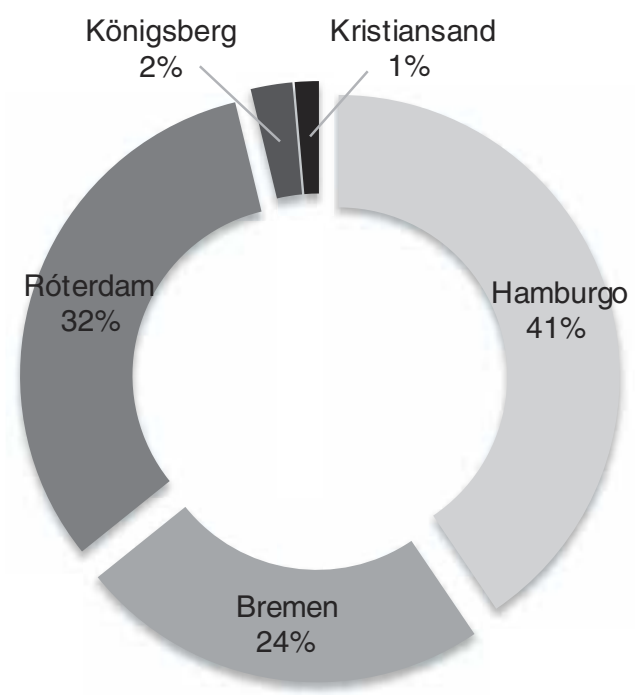

Fuente: elaboración propia a partir de AGA, diversos legajos.

En relación con esta cuestión, resulta muy elocuente la comunicación de la Dirección General de Comercio y Política Arancelaria, fechada en octubre de 1935, dirigida al Centro Oficial de Contratación de Moneda del Banco de España y remitida a su vez a las autoridades coloniales, en la que se expone la conveniencia de que, en ausencia de buques de pabellón nacional, se evite el transporte de madera con destino a Alemania mediante flotas extranjeras, al tiempo que se insta a que se realice en la mayor escala posible en buques alemanes, ya que, cuanto mayores sean los ingresos alemanes en concepto de fletes, más posibilidades habrá de que se incrementen las importaciones de madera de la colonia $^{49}$.

48. CDMH, fondo Político-Social-Documentación particular, caja 192, Blanco Elola, A., «Informe sobre las comunicaciones marítimas entre España y sus Posesiones del Golfo de Guinea», Madrid, 10/09/1932.

49. AGA, caja $81 / 6864$. 


\section{GRÁFICO 5}

Filiación de los buques madereros cargados en el continente (1933)

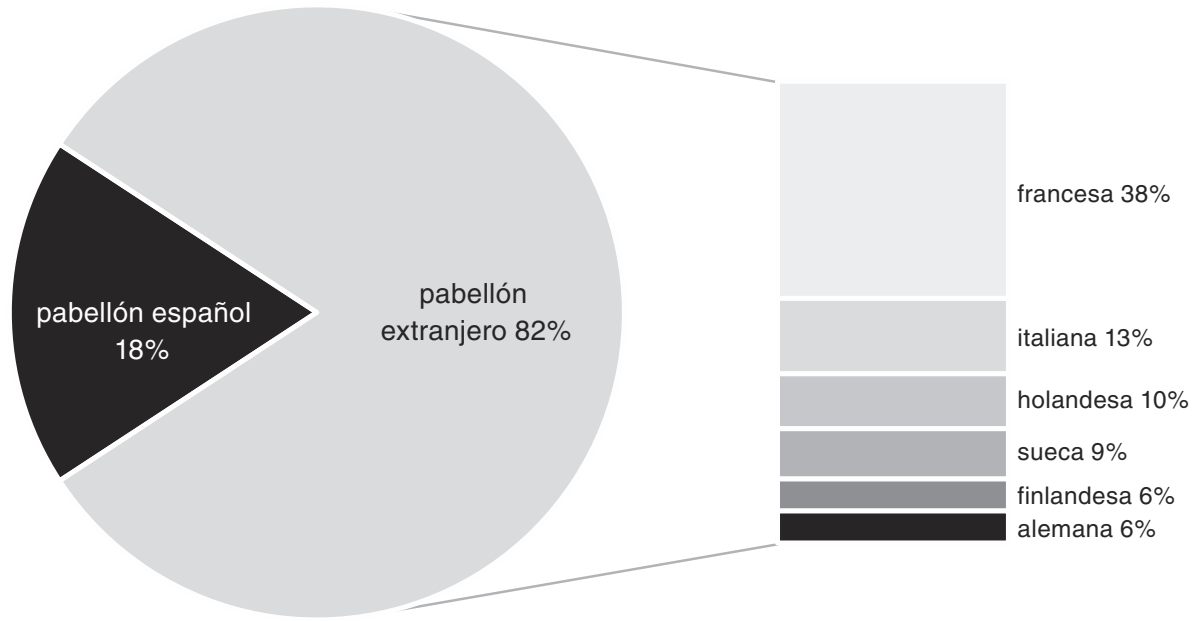

Fuente: elaboración propia a partir de AGA, diversos legajos.

Por otra parte, las condiciones arancelarias que regulan el comercio de la colonia española tampoco favorecen la competencia de los productores forestales con las compañías francesas exportadoras de ocume, al menos durante los primeros años. Con el fin de impulsar el incremento de los flujos comerciales con la metrópoli y estimular el abastecimiento de materias primas al mercado nacional, en 1922 se modifican parcialmente los aranceles de aduanas vigentes desde 1907 reduciendo los derechos arancelarios aplicables a las mercancías destinadas a la Península (haciendo abstracción de la bandera bajo la cual se realiza el transporte) e incrementando los gravámenes aplicables a los productos comercializados con otros países. En el caso de la madera, la producción exportada en trozas o piezas es gravada con la tarifa arancelaria de 5, 10 y 15 pesetas por metro cúbico, en función de su destino a la metrópoli, a nación convenida o a nación no convenida, respectivamente, mientras que la exportación de madera en tablas o tablones adeuda derechos por valor de 2, 5 y 10 pesetas por tonelada en función también de esos tres destinos ${ }^{50}$. En tal sentido, la documentación disponible sobre esta cuestión refleja las contradicciones entre la incapacidad del mercado nacional para absorber la producción forestal de la colonia, pese a la favorable política arancelaria, y las dificultades que al mismo tiempo provoca la cuantía superior de estas tarifas en comparación con las aplicables a la exportación de ocume del Gabón francés ${ }^{51}$.

50. Gaceta de Madrid, 14/03/1922; R. O. de 9 de junio de 1926, Boletín Oficial de los Territorios Españoles del Golfo de Guinea.

51. AGA, caja 81/6375. 


\section{CONCLUSIONES}

La recuperación de la demanda europea de ocume en la década de 1920, junto con la conquista efectiva de la región del Muni, la extensión por ella de las estructuras administrativas coloniales y los cambios normativos en el negocio de la madera que se producen a partir de 1926 estimulan la llegada de capitales financieros de origen español que dan lugar a la constitución de importantes compañías, las cuales, sin perder su carácter colonial, tienen en la madera su principal negocio. Estas compañías desarrollan hasta 1936 un conjunto de estrategias empresariales, productivas, comerciales y espaciales que les van a permitir desempeñar un papel hegemónico en la Guinea continental hasta la descolonización. Dichas estrategias incluyen la concentración empresarial; fuertes inversiones en capital técnico, con la mecanización temprana de determinadas operaciones como el tronzado y acarreo de la madera; la pugna por el incremento de la superficie concedida; la mejora progresiva en la calidad del ocume que se coloca en los mercados internacionales; así como el establecimiento en la colonia de instalaciones para una primera transformación de la madera.

En pocos años, los madereros coloniales consiguen matizar la posición de dominio que los productores del Gabón francés tienen en el abastecimiento europeo de ocume. Este hecho encierra una paradoja. El discurso forestal que se elabora sobre la colonia desde principios del siglo xx pone el acento en que su explotación va a hacer innecesaria la importación en España de no pocas clases de madera. En la práctica, éstas no se integran en los circuitos industriales metropolitanos más que para unas determinadas aplicaciones (el contrachapado) y en una pequeña proporción del total del volumen de madera extraído de la selva. Las compañías concesionarias ponen en práctica en la selva procedimientos de minería forestal: se busca el ocume intensamente y se obvia el resto.Y esta extracción, ni se realiza conforme a un plan explícitamente enunciado, ni va acompañada de trabajos silvícolas que garanticen la regeneración del ocume o el mantenimiento del capital que éste representa. La documentación deja entrever la necesidad de obtener beneficios con rapidez y justificar con resultados las fuertes inversiones realizadas.

La puesta en explotación capitalista de las selvas de la Guinea continental entronca con la historia social de la mano de obra africana. Como factor de producción, el acceso al bracero nativo es el cuello de botella de la agricultura de plantación de Fernando Póo, pero tiene un impacto más reducido en la economía forestal del continente. Desde un punto de vista social, la documentación muestra unas condiciones de trabajo duras, marcadas por el incumplimiento constante de los contratos de trabajo y de las normas coloniales que protegen al bracero, por la vida precaria de éste y por la presencia habitual del maltrato físico y moral. No obstante, esa misma documentación es poco transparente para 
comprender si el trabajo forestal facilita de alguna manera la aparición entre 1926 y 1936 de una clase proletaria negra, como sí que ocurre en otras colonias vecinas.

Desde un punto de vista territorial, se pasa de la explotación restringida a las inmediaciones de los tramos bajos de los cursos fluviales, que caracteriza a la tala indígena, a otra más extensa en el territorio. Aun así, no logra rebasar en estos primeros años -tampoco lo hará más tarde- el ámbito de una franja litoral relativamente cercana a la costa. La existencia de un escalón topográfico unas decenas de kilómetros hacia el interior hace imposible la evacuación por flotación de las maderas, y la imposibilidad financiera de la administración colonial para emprender obras viarias de envergadura reduce la "conquista» capitalista de las maderas del interior a sólo un enunciado teórico. No obstante, la concesión forestal articula el espacio colonial que a partir de este momento se construye en la Guinea continental. Se sobreimpone al espacio familiar y tribal en el que se desenvuelve la vida del nativo, y produce un nuevo espacio en el que domina la mercancía, el mercado y el salario.

El comienzo de la Guerra Civil española cierra en 1936 este período. A partir de ese momento se abre otro en la explotación forestal de la colonia que se caracteriza no sólo por ser más largo, sino también por las nuevas variables institucionales, políticas y económicas que aparecen en él. En cualquier caso, las bases ya se han asentado en la década precedente. En ese intervalo de tiempo la selva se coloniza a los ojos de la metrópoli, aunque lo más correcto sería afirmar que comienza su conquista colonial, capitalista e industrial.

\section{AGRADECIMIENTOS}

Los autores queremos mostrar nuestro agradecimiento a los evaluadores anónimos de $\mathrm{His}$ toria Agraria por la intensa labor realizada. Sus observaciones han sido trascendentes para mejorar el resultado final de este trabajo.

\section{REFERENCIAS}

ALENA (1931). La Compañia Nacional de Colonización Africana (A.L.E.N.A.) y sus negocios. Barcelona: Sucesores de Henrich.

ALENA (1936). La Compañia Nacional de Colonización Africana: Memoria correspondiente al ejercicio 1935. Barcelona: Artes Gráficas Studium.

ARIJA, J. (1930). La Guinea española y sus riquezas. Madrid: Espasa-Calpe. 
BRAVo, J. (1925). En la selva virgen del Muni. Madrid: Impr. Zoila Ascasibar.

CAmpos, A. (2005). Colonia, derecho y territorio en el golfo de Guinea:Tensiones del colonialismo español en el siglo xx. Quaderni fiorentini per la storia del pensiero giuridico moderno, 33-34 (2), 865-898.

CAPdevielle, J. M. (1947). El bosque de la Guinea: Exploración y explotación. Madrid: Dossat.

Carnero, F. \& DíAz de la PaZ, A. (2014). Aproximación a la economía de Guinea Ecuatorial durante el período colonial. Historia Contemporánea, (49), 707-734.

COGUISA (1931). Colonizadora de la Guinea Continental, S. A. Barcelona: Impr. Oliva de Vilanova.

Coquery-Vidrovitch, C. (2001). Le Congo au temps des grandes compagnies concessionnaires, 1898-1930. 2 t. Paris: Éditions de l'École des hautes études en sciences sociales. http://books.openedition.org/editionsehess/390

GARRIER, C. (2006). L'exploitation coloniale des forêts de Côte d'Ivoire: Une spoliation institutionnalisée. Paris: L'Harmattan.

Guerra, J. C. \& PASCuAl, H. (2015). Dominando la colonia: Cartografia forestal, negocio de la madera y apropiación del espacio en la antigua Guinea Continental española. Scripta Nova: Revista electrónica de geografía y ciencias sociales, 19 (525). http:// www.ub.es/ geocrit/sn/sn-525.pdf

Lanz, T. J. (2000). The Origins, Development and Legacy of Scientific Forestry in Cameroon. Environment and History, 6 (1), 99-120.

LASSERRE, G. (1955). Okoumé et chantiers forestiers du Gabon. Les Cahiers d'Outre-Mer. Revue de géographie de Bordeaux et de l'Atlantique, (30), 119-160.

López Morell, M. A. (2005). La Casa Rothschild en España. Madrid: Marcial Pons Historia.

Lynn, M. (2002). Commerce and Economic Change in West Africa: The Palm Oil Trade in the Nineteenth Century. Cambridge: Cambridge University Press.

MESSI, C. (2014). Les chantiers forestiers au Gabon: Une histoire sociale des ouvriers africains. Paris: L'Harmattan.

NÁJERA, F. (1930). La Guinea española y su riqueza forestal: Conferencia dada en el Instituto de Ingenieros Civiles el día 14 de diciembre de 1929. Madrid: Instituto Forestal de Investigaciones y Experiencias.

Nerín, G. (2010). La última selva de África: Antropófagos, misioneros y guardias civiles. Madrid: Los Libros de la Catarata.

Nerín, G. (2015). Corisco y el estuario del Muni (1470-1931): Del aislamiento a la globalización y de la globalización a la marginación. Paris: L'Harmattan.

NúÑEZ Romero, G. \& GonZÁlez RuIZ, L. (2008). Estado, ayuntamientos y fuerzas locales: El Banco de Crédito Local de España entre dos dictaduras. En L. GonZÁLEZ 
RUIZ \& J. M. MATÉs (Coords.), La modernización económica de los ayuntamientos: Servicios públicos, finanzas y gobiernos (pp. 373-395). Jaén: Universidad de Jaén.

PERPIÑÁ, R. (1945). De colonización y economía en la Guinea española. Barcelona: Labor.

PuYO, J.Y. (2001). Sur le mythe colonial de l'inépuisabilité des ressources forestières (Afrique occidentale française/Afrique équatoriale française, 1900-1940). Cahiers de géographie du Québec, 45 (126), 479-496.

Ramírez Copeiro del Villar, J. (2007). Trenes perdidos en África: Los ferrocarriles forestales en la Guinea española. Huelva: Jesús Ramírez Copeiro del Villar.

Río, F. DEL (1915). África occidental española (Sáhara y Guinea): Memoria elevada al Excmo. señor Ministro de Estado por el comandante de ingenieros D. Francisco del Río Foan. Madrid: Ministerio de Estado, Sección Colonial.

Rodríguez Esteban, J. A. (1996). Geografía y colonialismo: La Sociedad Geográfica de Madrid (1876-1936). Madrid: Universidad Autónoma de Madrid.

SuÁrez BosA, M. (2014). Atlantic Ports: An Interpretation Model. En M. SuÁRez BosA (Ed.), Atlantic Ports and the First Globalisation, c. 1850-1930 (pp. 1-18). Basingstoke: Palgrave McMillan.

TAno, K. P. (2016). Le bois dans l'économie de la Côte d'Ivoire (1880-1960). Paris: L'Harmattan.

TASCÓN, J. (2009). La caída de la inversión extranjera al final de la Segunda República española. Pasado y Memoria: Revista de Historia Contemporánea, (8), 35-73.

VALDÉs, L. (1928). Posesiones españolas en el Golfo de Guinea: Memoria redactada por el general de brigada D. Luis Valdés Cavanilles referente al viaje realizado a las posesiones españolas del Golfo de Guinea, acompañado del técnico holandés M.Van der Stok para el estudio de todas las posibilidades de explotaciones agrícolas y forestales a gran escala. Madrid: Impr. de Ramona Velasco. 